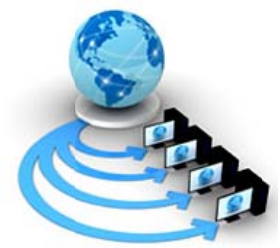

International Journal of Advanced Research in Computer Science

REVIEW ARTICLE

Available Online at www.ijarcs.info

\title{
ACCOUNTING AND BILLING OF PHYSICAL RESOURCES IN CLOUD FEDERATION: A REVIEW
}

\author{
Sameera Dhuria \\ Department of Computer Applications \\ Sri Guru Granth Sahib World University \\ Fatehgarh Sahib, India
}

\author{
Anu Gupta \\ Department of Computer Science and Applications \\ Panjab University \\ Chandigarh, India
}

\author{
R.K. Singla \\ Department of Computer Science and Applications \\ Panjab University \\ Chandigarh, India
}

\begin{abstract}
Cloud resources are provided to users on request and the bills are generated on the basis of resources actually consumed. Therefore, during periods of low demand, the idle resources may cause financial loss to Cloud Providers (CPs). While in peak load, user's request may be rejected due to insufficient resources. To manage this issue of under or over provisioning of resources, different CPs may voluntarily unite and efficiently utilize the resources in accordance with some agreement among them, thus creating a Federation of Clouds. Accounting and Billing of resources in such an environment is an important issue as inappropriate calculation of bills may either cause loss to CPs due to undercharging or to users by overcharging them. Taking this into consideration, this paper aims: To perform a literature review of the existing accounting and billing solutions in single CP and Federated Cloud Environment and; Identify the requirements and limitations of the existing accounting and billing methods so as to justify and support the need of a new framework for Accounting and Billing of infrastructural resources in Federation of Clouds.
\end{abstract}

Keywords: Cloud Computing; Federation; Accounting; Billing

\section{INTRODUCTION}

"Cloud Computing (CC) is an established paradigm which provides convenient, on demand network access to a shared pool of configurable computing resources (e.g., networks, servers, storage, applications, and services) that can be rapidly provisioned and released with minimal management effort or service provider interaction” [1]. Its features like no upfront investment, low operating cost, high scalability, easy access, reduced business and maintenance risk etc. [2] make it a much better option to use than traditional data centres [3].

In a standard CC model, resources of Cloud Providers (CPs) are shared among different customers. This introduces many challenges [4]. In case of shortage of resources, either new service requests of consumers are rejected or some other services that are already executing, with lower priority, are cancelled to accommodate new ones. This impacts the reputation of $\mathrm{CP}$ and makes the customers reluctant to use Cloud infrastructure, thus resulting in loss of revenue [5]. Usage of infrastructure of a single Cloud provider also makes it very difficult to provide adequate responsiveness and usability to users that are distributed at geographically different locations. All these problems generate the requirement of interconnecting Clouds i.e. creating Federation of Clouds. Cloud Federation allows sharing of resources among different CPs. This helps CPs to provide better Quality of Service (QoS) to users; apart from offering more reliable and flexible services to them [4].
In a federated cloud environment, different Cloud Service Providers (CSPs) are involved, each having its own different mechanism to charge customers for the resources consumed. Appropriate accounting and billing of cloud resources in such an environment is essential for both CSPs as well as customers and is a major area of concern [6]. Presence of resources of different CSPs may cause one to bear the cost of another if accounting is not properly done. It may also cause the customer to pay more if bills are not calculated properly. So there is a need to gain insight into the work done in this area of research. Till now, no systematic literature review has been performed for accounting and billing of resources in Cloud Federation or single CP environment that can summarize the work done so far in this particular area of research. Taking this into consideration, this paper reviews the existing literature of accounting and billing in both Single CP and Federated Cloud environment and identifies the requirements and limitations of current solutions. The limitations are further analysed to identify the need of a new framework for accounting and billing in a Federation of Clouds.

The paper is structured as follows. Section 2 gives the background and motivation for selecting accounting and billing for research. Section 3 highlights the review method. Accounting and Billing and its existing solutions in CC and Cloud Federation are discussed in Section 4. Requirements of Accounting and Billing are mentioned in Section 5. Limitations of existing solutions are discussed in Section 6. Section 7 concludes the paper. 


\section{BACKGROUND AND MOTIVATION}

At present, the usage patterns of many real-world applications is very dynamic and unpredictable e.g. Social networking sites like Facebook, MySpace etc. are used by millions of users. It is very difficult to predict the access and interaction pattern of such applications. This leads to over and under utilization of resources that are situated at different locations at different intervals of time [7]. Currently, there is no single Cloud provide that is capable of providing a huge infrastructure that can handle such applications having uncertain scalability with massive amounts of users accessing these services at different times, from different locations [8]. To cope up with such requirements, there is a need of easy migration of workloads and data from one CP to another or between private and public Clouds [9] i.e. interconnection of Clouds is required. One way of doing this is to create Federation of Clouds.

\section{A. Cloud Federation}

"It is a concept of service aggregation characterized by interoperability features, which addresses the vendor lock-in and provider integration problem.” [9]. Interoperability feature allows users to move easily to different CPs, if and when required. It also enables CPs to exchange and share resources in an efficient manner thus solving the problem of under or over provisioning of resources.

As a whole, Cloud Federation provides following benefits:

- During periods of peak loads, it helps in sharing resources in a cost-efficient manner and thus overcomes the requirement of over dimensioning the servers.

- In case of less demand of resources of a CP, its resources are provided to other CPs thus causing utilization of idle resources and generation of revenues.

- It enables interoperability among different CPs thus solving vendor lock-in problem [1].

Though Cloud Federation provides many benefits but some problems are associated with it. In [11], different issues related to Cloud Federation have been discussed:

- Portability (Virtual Machine (VM) Mobility, VM and Data Portability)

- Service Level Agreement (SLA) (Federated SLA Management, Federation Level Agreement, SLA Monitoring and Dependency, Legal Issues)

- Security (Trust, Authorization and Identity Management, Federated Policy and Semantic Interoperability)

- $\quad$ Economy (Market, Pricing, Accounting and Billing) etc. In this paper, the focus is on accounting and billing issue.

\section{B. Motivation}

Accounting systems track resource usage of various services, charge consumers for the resources consumed and generating revenues for their providers [12]. Currently, lack of a fair and transparent process of accounting and billing is one of the main reasons for hindering organizations from embracing Cloud. The process of accounting and billing of cloud resources also involves some issues which are discussed below. These issues create the requirement of studying and exploring this area of research in detail.

1) Issues:

\section{Related to customers}

- Users of Cloud computing have very less information about their actual consumption or usage of resources due to the black box nature of the datacenter's infrastructure. This makes it difficult for users to get an idea of expenditure of the services requested by them.

- CPs may incorrectly charge one user for the resources used by another. This is because resources are shared.

- Absolute isolation of all shared resources is not possible. This may cause externalities resulting in inflation in resource footprint of an application [13].

Related to CPs

- It is not easy for a CP to precisely monitor the consumption of all its resources and produce bills for the customers. The profitability of CPs is not clear. Therefore, some of the resources that are difficult to monitor may not be accounted completely, which eventually results in less income for CP.

- $\quad$ Sharing of resources imposes costs that are challenging to measure. Consequently, providers may incorrectly account for these costs, thereby, implicitly bearing additional costs and increasing their own operating expenses and thus, reducing their cost-effectiveness [13].

2) Benefits:

These issues can be solved with the help of appropriate accounting and billing mechanisms that will provide following benefits with respect to the above mentioned issues:

Customers related benefits

- Customers can make some idea of the cost footprint of their resources that are outsourced [13].

- $\quad$ Prevent overcharging. $C P$ related benefits

- Helps in estimating their Return on Investment.

- $\quad$ Prevents CPs from losing revenue due to undercharging [6].

As a whole, availability of appropriate accounting and billing mechanisms will encourage more customers to adopt clouds thereby reducing their infrastructural investment cost and enabling them to avail Cloud environment related other benefits. It will also be beneficial for CPs as their infrastructure utilization will be increased and their profit margins will improve [13].

From the above discussion, accounting and billing of cloud resources may be justified as a suitable area for further research.

\section{REVIEW METHOD}

Following major activities were performed in the review process:

A. Research Questions Formulation

This paper is aimed to answer following Research Questions:

Q1. What are the existing methods of Accounting and Billing in CC and Cloud Federation?

Q2. What are the limitations of these methods?

Q2. Is there any need of developing a new Accounting and Billing framework for Federated Cloud environment? 


\section{B. Defining search string}

To carry out the literature review process, search was conducted in databases like Springer, Elsevier, ACM, IEEE digital library etc. to find relevant papers.

The database sources were searched using search strings that consisted of different combinations of the following keywords:

Accounting, Billing, Charging, Pricing, Payment, Metering, Monitoring, Cloud Computing, Cloud Federation, Federated Cloud

\section{Application of Inclusion/Exclusion criteria}

On applying the search strings, a large number of papers were obtained. All of these were not relevant to this specific study. Therefore, from the search results, only those publications have been considered that satisfied the following inclusion/exclusion criteria:

Inclusion Criteria:

- If similar kind of work is done in more than one publication of the same author, with not much significant difference, then only the latest one has been included.

Exclusion Criteria:

Those publications were excluded that

- Discussed accounting and billing process in general but not with respect to CC or Cloud Federation.

- Focused solely on just one particular aspect or function or feature of accounting and billing (e.g. energy consumption, pricing etc.) and did not consider any of the other functions or characteristics of accounting and billing process.

The inclusion/exclusion criteria were initially applied only on titles as well as abstracts. In case of any non -clarity, complete paper was reviewed to decide whether it has to be included or not.

After applying the inclusion/exclusion criteria, 14 primary studies and 1 secondary study have been identified that are relevant from the point of view of Research Questions formulated and the area on which we are focusing upon.

It is worth mentioning here that accounting and billing solutions for Grid Computing, Service Oriented Architectures etc. have not been considered. Though these technologies are related to CC, but they are out of scope for this paper.

\section{ACCOUNTING AND BILLING}

\section{A. Accounting and Billing process}

Cloud accounting and billing refers to how resource usage is recorded in Cloud environmrent and charged [14]. Very few studies have explained the complete process of Accounting and Billing with respect to CC or Cloud Federation. An overview of accounting and billing process described in 3 selected studies $[3,15,16]$ is given here.

Agundez et al. [15] presented following taxonomy of accounting process for services on Internet which is also applicable to CC.

- Metering: Information related to the resource usage of a user's service is collected by this function.
- Mediation: It performs the task of converting records collected by metering function into some data format that can easily be stored and processed.

- Accounting: The information related to resource usage of service(s) of consumer is collected and filtered by this process.

- $\quad$ Roaming: This function allows usage of multiple Cloud providers. Customer deals with a single CP without knowing where its requested services are actually being run.

- Pricing: Resources requested by a user are obtained from CP at a certain price.

- Charging: A pricing function is applied to the usage records of requested resources to convert them into monetary units. This way, the cost of resource usage is collected by this process.

- Billing: Final Bills for users are generated by summarizing the charge records of requested services of a given time period and indicating the amount to be paid by users in monetary units.

- Financial clearing: All the activities beginning from the commitment of providing service to bills generation are included in this function. Broadly, it implies the bill payment.

Two studies [3] [16], have explained Accounting and billing process with respect to CC itself. Three basic services (components) of an accounting system are [16]: metering, accounting and billing.

- Resource Usage data is collected by the metering service component at the service interface. It stores this data and makes it accessible to accounting service which further uses it for accounting purpose.

- After retrieving resource usage data from metering service, the accounting service calculates resource consumption from it and makes it available to the billing service, which uses the accounting data and computes bills.

In Lindner et al. [3], the functions of accounting and Billing process have been mentioned as sub processes of service provisioning process. Apart from service deployment, that defines the service in terms of service components and associated meta-data, other sub-processes and their functions discussed in this study are:

- Infrastructure monitoring: This process measures hardware related metrics of VMs which deploy the actual applications. Examples of metrics that are measured are CPU usage, bandwidth usage, memory usage etc.

- $\quad$ Service Monitoring: Key Performance Indicators (KPIs) of running VMs of a service are measured here. KPIs are related to the operation and status of the service. This process also checks for implementation of SLAs and gives notifications if there is any violation in fulfillment of SLA.

- Service Accounting: Retrieval of resource usage information of VMs in the form of records is the main task of this process. SLA violations and usage data are obtained from service and infrastructure monitoring processes respectively.

- $\quad$ Service Billing: Keeping in view the prices of resources used by VMs and other rules for billing, bills are produced by this process using accounting records. 
B. Current solutions of Accounting and Billing

The work done by researchers in the area of accounting and billing in CC and Cloud Federation is summarized below:
1) Primary studies

The year-wise distribution of studies identified in Section 3 is shown in Figure 1.

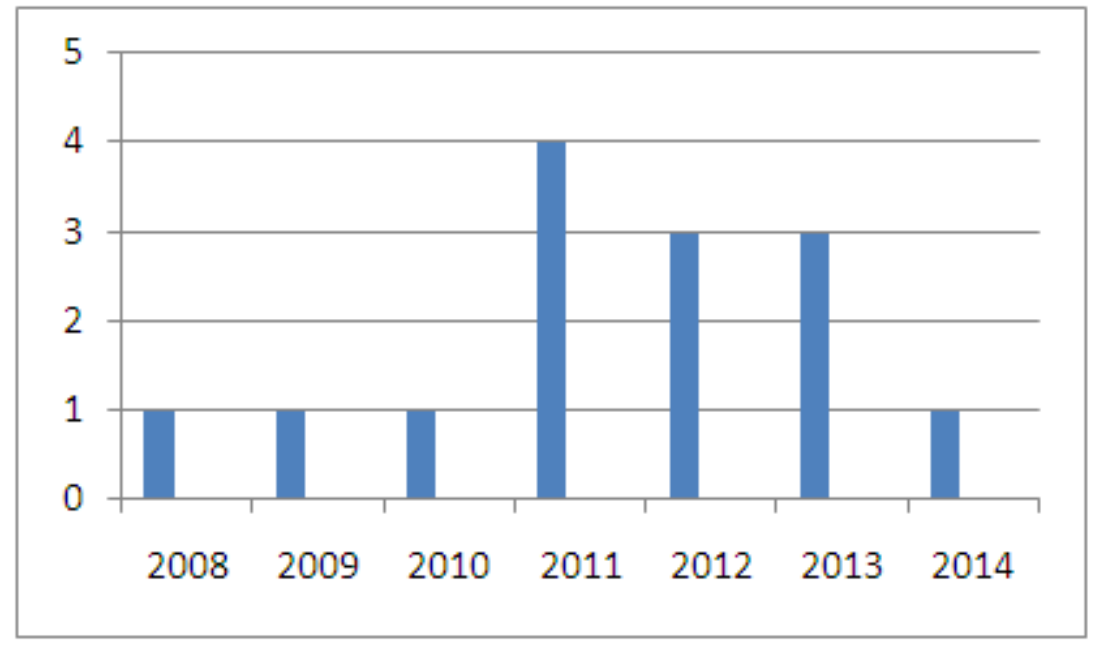

Figure 1 Year-wise distribution of selected studies

These studies have been briefed in the below table with respect to their area of focus, kind of cloud environment and service model in which their work is applicable, year of publication and citation count. It is also mentioned in the table whether the research work done has been verified/ evaluated and whether it is a part of some research project.

Table 1. Accounting and Billing solutions in CC and Cloud Federation

\begin{tabular}{|c|c|c|c|c|c|c|}
\hline Study & Focus & $\begin{array}{l}\text { Kind of Cloud } \\
\text { Environment }\end{array}$ & $\begin{array}{l}\text { Service } \\
\text { Model }\end{array}$ & $\begin{array}{c}\text { Verification/ } \\
\text { Evaluation of } \\
\text { solution }\end{array}$ & $\begin{array}{c}\text { Research } \\
\text { Project }\end{array}$ & Citations \\
\hline [3] & $\begin{array}{l}\text { Definition and components of } \\
\text { Cloud Supply Chain }\end{array}$ & $\begin{array}{l}\text { Single Cloud } \\
\text { Provider }\end{array}$ & IaaS & No & Yes & 50 \\
\hline [17] & $\begin{array}{l}\text { Billing based on Leasing } \\
\text { Instances model }\end{array}$ & $\begin{array}{l}\text { Single Cloud } \\
\text { Provider }\end{array}$ & IaaS & Yes & Yes & 12 \\
\hline [18] & Accounting model for CC & $\begin{array}{l}\text { Single Cloud } \\
\text { Provider }\end{array}$ & $\begin{array}{l}\text { IaaS } \\
\text { PaaS } \\
\text { SaaS }\end{array}$ & Yes & No & 12 \\
\hline [19] & Real Time Rating and Charging & Cloud Federation & $\begin{array}{l}\text { IaaS } \\
\text { PaaS } \\
\text { SaaS }\end{array}$ & No & Yes & 4 \\
\hline [1] & $\begin{array}{l}\text { Accounting and Billing between } \\
\text { consumer and Infrastructure } \\
\text { Provider }\end{array}$ & Cloud Federation & IaaS & No & Yes & 99 \\
\hline [20] & $\begin{array}{l}\text { Storage access billing based on } \\
\text { exertion }\end{array}$ & $\begin{array}{l}\text { Single Cloud } \\
\text { Provider }\end{array}$ & IaaS & No & No & 25 \\
\hline [12] & $\begin{array}{l}\text { Scalable Accounting for prepaid } \\
\text { Services }\end{array}$ & $\begin{array}{l}\text { Single Cloud } \\
\text { Provider }\end{array}$ & IaaS & Yes & Yes & 4 \\
\hline [21] & $\begin{array}{l}\text { Secure, non-obstructive and } \\
\text { mutually verifiable billing }\end{array}$ & $\begin{array}{l}\text { Single Cloud } \\
\text { Provider }\end{array}$ & IaaS & Yes & No & 39 \\
\hline [13] & Verifiable resource accounting & $\begin{array}{l}\text { Single Cloud } \\
\text { Provider }\end{array}$ & IaaS & No & No & 60 \\
\hline$[6]$ & Verification of Billable events & $\begin{array}{l}\text { Single Cloud } \\
\text { Provider }\end{array}$ & IaaS & Yes & Yes & 4 \\
\hline [22] & $\begin{array}{lll}\text { Consumer } & \text { side } & \text { resource } \\
\text { accounting } & & \\
\end{array}$ & $\begin{array}{l}\text { Single Cloud } \\
\text { Provider }\end{array}$ & IaaS & Yes & No & 5 \\
\hline [23] & Online Billing System & $\begin{array}{l}\text { Single Cloud } \\
\text { Provider }\end{array}$ & IaaS & Yes & No & 23 \\
\hline
\end{tabular}




\begin{tabular}{|c|l|c|c|c|c|c|}
\hline$[16]$ & $\begin{array}{l}\text { Accounting by both customer } \\
\text { and provider }\end{array}$ & $\begin{array}{c}\text { Single Cloud } \\
\text { Provider }\end{array}$ & IaaS & Yes & 10 \\
\hline$[24]$ & Verifiable resource accounting & $\begin{array}{c}\text { Single Cloud } \\
\text { Provider }\end{array}$ & IaaS & Yes & Yes \\
\hline
\end{tabular}

Table 2 mentions some of the important functions and characteristics of an accounting and billing process identified from the literature, along with the studies in which they have been considered or discussed.

Table 2. Functions and characteristics

\begin{tabular}{|c|c|c|}
\hline \multicolumn{2}{|c|}{ Accounting and Billing } & Study \\
\hline \multirow{4}{*}{ Functions } & $\begin{array}{l}\text { SLA monitoring or violation } \\
\text { compensation }\end{array}$ & [1], [3], [13], [19], [21], \\
\hline & Resource Usage Monitoring & $\begin{array}{l}\text { [1], [3], [6], [12], [13], [16], [18], } \\
\text { [21], [22], [24] }\end{array}$ \\
\hline & Payment Method & [1], [3], [12], [17], [19], [23] \\
\hline & Pricing Mechanism & $\begin{array}{l}\text { [1], [3], [12], [13], [16], [17], [18], } \\
{[19],[22],[23],[24]}\end{array}$ \\
\hline \multirow{4}{*}{ Characteristics } & Security & {$[6],[13],[21],[23],[24]$} \\
\hline & Graphical User Interface & {$[1],[18],[19],[23],[24]$} \\
\hline & Verifiability & {$[6],[13],[16],[21],[24]$} \\
\hline & Revenue Sharing & [19] \\
\hline
\end{tabular}

Publication details of the studies are shown in Table 3.

Table 3. Publication details

\begin{tabular}{|c|l|l|l|}
\hline $\begin{array}{c}\text { Sr. } \\
\text { No. }\end{array}$ & Database & $\begin{array}{c}\text { Conference/ } \\
\text { Journal/ Workshop }\end{array}$ & Studies \\
\hline 1. & \multirow{2}{*}{ IEEE } & Conference & $\begin{array}{l}{[1], \quad[12],} \\
{[19]}\end{array}$ \\
\cline { 3 - 4 } & & Journal & {$[21]$} \\
\hline 2. & \multirow{2}{*}{ Springer } & Conference & $\begin{array}{l}{[16], \quad[17],} \\
{[22]}\end{array}$ \\
\cline { 3 - 4 } & & & \\
\hline 3. & \multirow{2}{*}{ ACM } & Workshop & {$[13]$} \\
\cline { 3 - 4 } & & Conference & {$[6]$} \\
\cline { 3 - 4 } & & Journal & {$[24]$} \\
\hline 4. & \multirow{2}{*}{ Others } & $\begin{array}{l}\text { Workshop on Hot } \\
\text { Cloud }\end{array}$ \\
\cline { 3 - 4 } & & Journals & {$[18],[23]$} \\
\hline
\end{tabular}




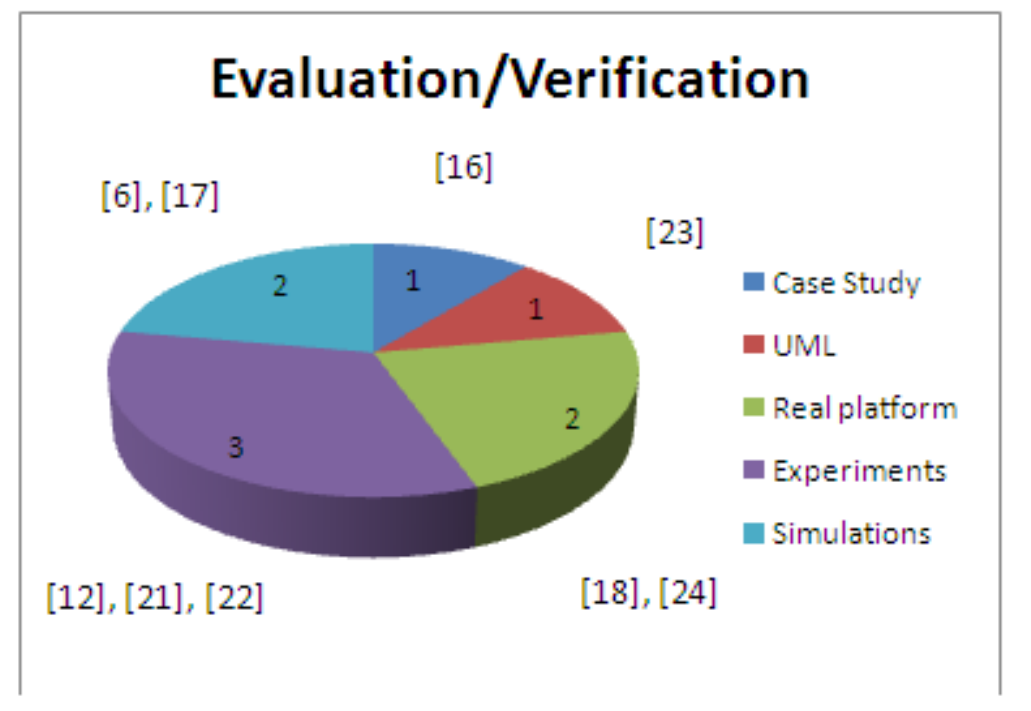

Figure 2 evaluation/verification methods

\section{2) Secondary Study}

The identified secondary study [25] has taken into account just 4 accounting models and analysed them with respect to taxonomy of accounting and billing process presented by [15] and some other features. Other studies and their contribution have not been considered.

As a whole, a comprehensive and thorough literature review of this particular research area has not been provided in the secondary study.

\section{Key Findings}

Below mentioned are the key findings from the analysis of the papers studied:

- This area of research has not been explored much by the researchers. Despite the importance of this area, it has not received much attention of research community.

- Complete process of accounting and billing has been discussed in very few papers. Existing research in this area is focused on different aspects of accounting and billing like security, real time accounting etc.

- All the functions and characteristics of an accounting and billing process have not been covered in any of the existing solutions.

- Most of the work is focused on IaaS service model of CC.

- Most of the mechanisms or solutions proposed in the literature for accounting and billing are not very transparent and details of the same are not completely available.

- In many studies, only conceptual work has been done and subsequent studies for implementation part are not available.

- The solutions presented and many of the features discussed in these papers like security, verifiability etc. have not been embraced in commercial cloud solutions.

\section{REQUIREMENTS OF ACCOUNTING AND BILLING}

Cloud environment has some specific requirements that must be fulfilled by an accounting and billing solution. The requirements of Accounting and Billing process, as mentioned in [1], have been discussed below under two broad categories:

General Requirements applicable to both Single CP as well as Cloud Federation

1. Service Elasticity: An accounting and billing system must be able to handle the VM requirements of a given service, that may increase or decrease, while in execution.

2. Service Billing: A service request may consist of a number of VMs. Bills must be generated collectively for all these VMs instead of individually for each VM.

3. Complex Pricing: Resources must be priced based on distinguishing factors and characteristics like usage history of user, CP's workload etc.

4. Adaptable Design: The accounting system must be able to manage with the addition of any new hardware/software related metrics or any other changes in the system's working.

5. Flexible Data Format: Accounting and billing must be done considering both hardware as well as software related metrics.

6. SLA Violation Compensation: Accounting must be done for both resource consumption and any violations in SLA [1].

Requirements specifically with respect to Cloud Federation

1. Dynamic relocation of VM: In Cloud Federation, VMs of a service may run on one or more sites. This is because in case of shortage of resources, a CP may outsource some of the VMs. So, a VM may be migrated to another CP while in execution. Accounting system must accommodate this relocation of running VMs i.e. accounting must be done appropriately for VMs running both at local as well as remote datacenters.

2. Inter-site Billing: Two kinds of billing are required in Federated Cloud Environment: a) between the CP and 
the user and (b) among different CPs that collaborate to form Cloud Federation (also called Inter-site billing). The system must be able to manage both kinds of billing. [1]

Apart from the requirements mentioned in [1], some other challenges that need to be addressed for accounting and billing in Cloud Federation are:

- Appropriate pricing mechanism for resources in a Cloud Federation: Pricing mechanism in a federated cloud environment is different from single CP environment. In Cloud Federation, it is necessary to take into consideration pricing mechanism of each other while charging customers for the resource usage. What prices will be given to the resources in such a heterogeneous environment is an important issue because different CPs may have different prices for their resources.

- Revenue sharing mechanism among different CPs: The revenue generated by renting infrastructure in Cloud Federation must be shared in an appropriate way.

- Penalty for violating Federation Level Agreement (FLA): As FLA's are built on top of existing SLA's between user and CP as well as between different CPs constituting Cloud Federation, it is difficult to identify and compensate for violations in such an agreement.

\section{LIMITATIONS OF EXISTING SOLUTIONS WITH RESPECT TO CLOUD FEDERATION}

- $\quad$ Till now, not much work has been performed in the area of accounting and billing of cloud resources especially with respect to federated cloud environment. Very few papers are available in the literature which address accounting and billing in cloud federation. As a result, till now, no method of accounting and billing (in single Cloud environment or Cloud Federation) exist that addresses all the requirements mentioned in section $\mathrm{V}$.

- Commercial CPs like AWS has their own mechanisms of accounting based on their own specific requirements and no federation aspects are covered by their solutions [19].

- One paper in literature [1] that is focused on Cloud Federation, has proposed a solution that tries to fulfill some of the identified requirements. But the proposed solution has some limitations:

1.) The solution presented is limited to RESERVOIR [26] project.

2.) Problem of inter-site billing has not been addressed.

3.) Pricing, FLA management and revenue distribution related details have not been included in the proposed solution.

From the discussion in section IV and V, and the identified limitations, it is clear that existing methods of accounting and billing of cloud resources are not directly applicable in Federated environment and all the requirements of Cloud Federation have not been addressed by any of the available solutions. So there is a need to develop a new framework for Accounting and Billing in Federation of Clouds.

\section{CONCLUSION}

Cloud Federation is a new paradigm that facilitates sharing of resources of different providers among each other. This helps in preventing rejection of user's requests when provider does not have sufficient resources and also allows a provider with underused resources to make them available to others. Appropriate accounting and billing of resources is important in Federated Cloud environment as well as single CP environment. But this area has not yet received much attention from the research community especially in case of Cloud Federation. This is mainly because Cloud Federation has itself emerged as a new field of research in recent years. This paper consolidates and summarizes the work done in the area of accounting and billing in CC as well federated cloud environment, identifies its limitations and requirements. 14 primary studies and 1 secondary study have been selected for review. The analysis of the existing literature shows that single commercial CSPs use their own different mechanisms to charge customers for the resources consumed. These mechanisms are not very transparent and details of the same are not completely available. They also do not fulfil the requirements of accounting and billing of heterogeneous environment of Cloud Federation. From this review, the need to develop a new framework for accounting and billing in federated cloud environment that must consider all the requirements of Cloud Federation that have not been addressed so far in any solution available in the literature, is justified.

\section{REFERENCES}

[1] Elmroth, E., Marquez, F., Henriksson, D., and Ferrera, D.: Accounting and billing for Federated Cloud infrastructures. In: 2009 8th International Conference on Grid and Cooperative Computing, pp. 268-275. IEEE (2009).

[2] Zhang, Q., Cheng, L. and Boutaba, R.: Cloud computing: state-of-the-art and research challenges. Journal of internet services and applications. 1(1) 7-18 (2010).

[3] Lindner, M., Galan, F., Chapman, C., Clayman, S., Henriksson, D. and Elmroth, E.: The Cloud supply chain: A framework for information, monitoring, accounting and billing. In: 2010 2nd International ICST Conference on Cloud Computing, 2010.

[4] Grozev, N. and Buyya, R.: Inter-Cloud architectures and application brokering: Taxonomy and survey. Software: Practice and Experience. 44(3), 369-390 (2014).

[5] Armbrust, M., Fox, A., Griffith, R., Joseph, A.D., Katz, R.H., Konwinski, A., Lee, G., Patterson, D.A., Rabkin, A., Stoica, I. and Zaharia, M.: Above the clouds: A berkeley view of cloud computing. In: Technical Report UCB/EECS2009-28, Vol. 17, EECS Department, University of California, Berkeley.

[6] Chen, L. and Chen, K.: BitBill: Scalable, Robust, Verifiable Peer-to-Peer Billing for Cloud Computing. In: HotCloud (2014).

[7] Buyya, R., Ranjan, R. and Calheiros, R.: Intercloud: Utilityoriented federation of cloud computing environments for scaling of application services. In: 2010 International Conference on Algorithms and Architectures for Parallel Processing, pp.13-31. Springer Berlin Heidelberg (2010).

[8] Clayman, S., Toffetti, G., Galis, A. and Chapman, C.: Monitoring services in a federated cloud-the reservoir experience. In: Achieving Federated and Self-Manageable Cloud Infrastructures: Theory and Practice, pp. 242-265. IGI Global (2012).

[9] Lewis, G. A.: Role of Standards in Cloud-Computing Interoperability. In: 2012 46th Hawaii International Conference on System Sciences, pp. 1652-1661. 2012.

[10] Kurze, T., Klems, M., Bermbach, D., Lenk, A., Tai, S. and Kunze, M.: Cloud Federation. In : Proceedings of the Second 
International Conference on Cloud Computing, GRIDs, and Virtualization, pp. 32-38. 2011.

[11] Toosi, A.N., Calheiros, R.N. and Buyya, R.: Interconnected cloud computing environments: Challenges, taxonomy, and survey. ACM Computing Surveys (CSUR). 47(1) 7 (2014).

[12] Xu, L., Lakew, E.B., Hernandez-Rodriguez, F. and Elmroth, E.: A scalable accounting solution for prepaid services in cloud systems. In: 2012 Ninth IEEE International Conference on Services Computing (SCC), pp. 81-89. IEEE (2012).

[13] Sekar, V., and Petros, M.: Verifiable resource accounting for cloud computing services. In: 2011 Proceedings of the 3rd ACM workshop on Cloud computing security workshop, pp. 21-26. ACM (2011)

[14] da Silva, F.A.P., Neto, P.A.D.M.S., Garcia, V.C., Trinta, F.A.M. and Assad, R.E.: Monext: An Accounting Framework for Infrastructure Clouds. In: $201312^{\text {th }}$ IEEE International Symposium on Parallel and Distributed Computing (ISPDC), pp. 26-33. IEEE (2013).

[15] Ruiz-Agundez, I., Penya, Y.K. and Bringas, P.G.: A taxonomy of the future internet accounting process. In: Fourth International Conference on Advanced Engineering Computing and Applications in Sciences. 2010.

[16] Molina-Jimenez, C., Cook, N. and Shrivastava, S.: On the feasibility of bilaterally agreed accounting of resource consumption. In: 2008 International Conference on ServiceOriented Computing, pp. 270-283. Springer Berlin Heidelberg (2008.)

[17] Yuan, Q., Liu, Z., Peng, J., Wu, X., Li, J., Han, F., Li, Q., Zhang, W., Fan, X. and Kong, S.: A leasing instances based billing model for cloud computing. In: International Conference on Grid and Pervasive Computing, pp. 33-41. Springer Berlin Heidelberg (2011).

[18] Ruiz-Agundez, I., Penya, Y.K. and Bringas, P.G.:Cloud computing services accounting. International Journal of Advanced Computer Research (IJACR), 2(2) 7-17 (2012).
[19] Flake, S., Tacken, J. and Zoth, C.: Real-time rating and charging in federated cloud environments. In: $201217^{\text {th }}$ IEEE Conference on Emerging Technologies \& Factory Automation (ETFA), pp. 1-6. IEEE (2012).

[20] Wachs, M., Xu, L., Kanevsky, A. and Ganger, G.R.: Exertion-based Billing for Cloud Storage Access. In: HotCloud. 2011.

[21] Park, K.W., Han, J., Chung, J. and Park, K.H.: THEMIS: A Mutually verifiable billing system for the cloud computing environment. IEEE Transactions on Services Computing. 6(3), 300-313 (2013).

[22] Mihoob, A., Molina-Jimenez, C. and Shrivastava, S.: Consumer side resource accounting in the cloud. In: Conference on e-Business, e-Services and e-Society, pp. 58-72. Springer Berlin Heidelberg (2011).

[23] Singh, S., and Chana, I.: Advance billing and metering architecture for infrastructure as a service. International Journal of Cloud Computing and Services Science. 2(2), 123 (2013):

[24] Chen, C., Maniatis, P., Perrig, A., Vasudevan, A. and Sekar, V.: Towards verifiable resource accounting for outsourced computation. ACM Sigplan Notices. 48(7). 167-178 (2013).

[25] da Silva, F.A.P., Neto, P.A.D.M.S., Garcia, V.C., Assad, R.E. and Trinta, F.A.M.: Accounting models for cloud computing: A systematic mapping study. In: Proceedings of the International Conference on Grid Computing and Applications (GCA). The Steering Committee of The World Congress in Computer Science, Computer Engineering and Applied Computing (WorldComp), 2012.

[26] Rochwerger, B., Breitgand, D., Levy, E., Galis, A., Nagin, K., Llorente, I.M., Montero, R., Wolfsthal, Y., Elmroth, E., Caceres, J. and Ben-Yehuda, M.: The reservoir model and architecture for open federated cloud computing. IBM Journal of Research and Development. 53(4), 4-1 (2009). 